\title{
Pelayanan Karyawan, Harga Yang Sesuai Daya Beli Dan Lokasi Faktor Penentu Kepuasan Konsumen
}

\author{
Safira Khoirunnisa ${ }^{1}$, Siska Maya ${ }^{2 *}$ \\ ${ }^{1,2}$ Fakultas Ilmu Pendidikan dan Pengetahuan Sosial Universitas Indraprasta PGRI \\ Jl. Raya Tengah No.80, Gedong, Kec. Ps. Rebo, Kota Jakarta Timur, Daerah Khusus Ibukota Indonesia, Indonesia \\ *may3110@yahoo.com
}

\begin{abstract}
The influence of service quality, price and location on consumer satisfaction of micro-enterprises in the market. The research method used is a survey research method. That is research to determine the effect of independent variables (quality of service, price and location) with related variables (consumer satisfaction). The population in this study are all micro business consumers who have purchased the product more than once in a market transaction with an unknown population. The specified sample is 100 people using non-probability sampling technique. From the results of multiple linear regression analysis shows that the variables of Service Quality $(X 1)=0.297$, Price $(X 2)=0.392$, and Location $(X 3)=0.272$ on consumer satisfaction. The analysis of the coefficient of determination (R2) is $0.754 \mathrm{or} 75.4 \%$. The magnitude of the coefficient of determination indicates that the independent variables consisting of Service Quality (X1), Price (X2) and Location (X3) are able to explain the dependent variable, namely Consumer Satisfaction (Y) of 47.2\%, while the remaining 52.8\% explained by other variables not included in this research model. The influence of each variable is the variable of service quality, price and location partially positive and significant effect on consumer satisfaction in the market.
\end{abstract}

Keywords : Quality of Service, Price, Location and Customer Satisfaction

\begin{abstract}
Abstrak- Pengaruh kualitas pelayanan, harga dan lokasi terhadap kepuasan konsumen usaha mikro dipasar. Metode penelitian yang digunakan adalah metode penelitian survey. Yaitu penelitian untuk mengetahui pengaruh antara variabel bebas (kualitas pelayanan, harga dan lokasi) dengan variabel terkait (kepuasan konsumen). Populasi dalam penelitian ini adalah semua konsumen usaha mikro yang telah membeli produk lebih dari satu kali transaksi di pasar dengan jumlah populasi yang tidak diketahui. Sampel yang ditentukan berjumlah 100 orang menggunakan teknik nonprobability sampling. Dari hasil analisis regresi linier berganda menunjukkan bahwa variabel Kualitas Pelayanan $(X 1)=0,297$, Harga $(X 2)=0,392$, dan Lokasi $(X 3)=0,272$ terhadap Kepuasan Konsumen. Analisis nilai koefisien determinasi (R2) sebesar 0,754 atau 75,4\%. Besarnya nilai koefisien determinasi tersebut menunjukkan bahwa variabel independen yang terdiri dari Kualitas Pelayanan (X1), Harga (X2) dan Lokasi (X3) mampu menjelaskan variabel dependen yaitu Kepuasan Konsumen (Y) sebesar 47,2\%, sedangkan sisanya sebesar 52,8\% dijelaskan oleh variabel lain yang tidak dimasukkan dalam model penelitian ini. Pengaruh masing-masing variabel adalah variabel kualitas pelayanan, harga dan lokasi secara parsial berpengaruh positif dan signifikan terhadap kepuasan konsumen udaha mikro dipasar.
\end{abstract}

Kata Kunci : Kualitas Pelayanan, Harga, Lokasi dan Kepuasan Konsumen

\section{PENDAHULUAN}

Perusahaan yang bergerak di bidang Mikro juga harus pandai dalam memilih lokasi sebagai tempat perusahaan tersebut untuk melakukan kegiatan berdagang, karena dengan lokasi yang strategis dan nyaman akan lebih menguntungkan[1]. Memilih lokasi yang terletak di keramaian atau mudah dijangkau oleh calon konsumen dapat dijadikan sebagai salah satu strategi yang dapat dilakukan oleh pemilik usaha. Seorang maupun sekelompok orang cenderung memilih lokasi dekat dengan aktivitasnya[2]. Lokasi yang baik menjamin tersedianya akses yang cepat, dapat menarik sejumlah besar konsumen dan cukup kuat untuk mengubah pola pembalian konsumen. Mood dan respon pelanggan dipengaruhi secara signifikan oleh lokasi, desain dan tata letak fasilitas jasa. Maka mood dan respon inilah yang nantinya bisa memunculkan kepuasan atau ketidakpuasan konsumen. Ketidakpuasan pelanggan adalah respon pelanggan terhadap ketidaksesuain yang dirasakan dengan harapan sebelumnya[3].

Kepuasan konsumen merupakan suatu tingkat dimana kebutuhan, keinginan dan harapan dari pelanggan dapat terpenuhi yang akan mengakibatkan terjadinya pembelian ulang atau kesetiaan yang berlanjut. Semakin terpenuhi harapan-harapan dari konsumen tentu konsumen akan semakin puas. Sebuah usaha harus menpunyai strategi-strategi dalam menjual[4], agar konsumen dapat dipertahankan keberadaannya atau lebih ditingkatkan lagi jumlahnya. Jika konsumen merasa puas, maka ia akan melakukan pembelian secara berulang-ulang. Kepuasan 
pelanggan merupakan faktor yang sangat menentukan dalam pemasaran, sebaliknya kekecewaan pelanggan dalam memberi layanan bisa menjadikan kehancuran usaha dimasa mendatang[5]. Agar pelanggan dapat dipertahankan, tentu harus dilakukan dengan langkahlangkah pelayanan optimal bagi pelanggan. Identifikasi permasalahnnya, yaitu [6], [7]: a.) Adanya persaingan dalam usaha mikro yang berada di sekitar lokasi. b.) Tingkat kepuasan konsumen yang kurang optimal yang berpengaruh terhadap kurangnya pengunjung yang cenderung menurun. Dengan melihat hal-hal yang berkaitan dengan latar belakang yang telah dipaparkan diatas maka penulis ingin mengetahui hal-hal yang berkaitan nya dengan pelayanan yang diberlakukan pada pedagang usaha mikro terhadap konsumen atau pelanggannya oleh karena itu penulis merumuskan masalah sebagai berikut : a.) Seberapa besar pengaruh kualiatas pelayanan terhadap kepuasan konsumen pada usaha mikro. b.) Sebarapa besar pengaruh harga terhadap kepuasan konsumen pada usaha mikro. c.) Sebarapa besar pengaruh lokasi terhadap kepuasan konsumen pada usaha mikro. Tujuan penelitian ini : a.) untuk mengetahui pengaruh kualitas pelayanan terhadap kepuasan konsumen usaha mikro. b.) untuk mengetahui pengaruh harga terhadap kepuasan konsumen usaha mikro. c.) untuk mengetahui pengaruh lokasi terhadap kepuasan konsumen usaha mikro.

\section{a. Kepuasan Konsumen}

\section{KAJIAN PUSTAKA}

Kepuasan adalah perasaan senang atau kecewa yang berasal dari perbandiangan antara kesannya terhadap kinerja atau hasil suatu produk dan harapan-harapannya[8], [9]. Dari definisi tersebut merupakan fungsi dari persepsi atau kesan atas kinerja dan harapan.

Secara umum kepuasan (satisfication) adalah perasaan senang atau kecewa seseorang yang timbul karena membandingkan kinerja yang dipersepsikan produk (atau hasil) terhadap ekspetasi mereka[7].

Selain itu terdapat beberapa penelitian yang mengungkapkan bahwa kepuasan konsumen adalah konsep sentral dalam wacana bisnis manajemen[10].

\section{b. Kualitas Pelayanan}

Kualitas pelayanan adalah upaya penyampaian jasa untuk memenuhi kebutuhan dan keinginan pelanggan serta ketepatan penyampaian untuk mengimbangi harapan pelanggan[7]. Harapan konsumen merupakan keyakianan konsumen sebelum mencoba atau membeli suatu produk yang dijadikan sebagai acuan dalam menilai kinerja produk tersebut.

Kualitas pelayanan menjadi suatu keharusan yang harus dilakukan oleh perusahaan atau suatu usaha mikro supaya mampu bertahan dan tetap mendapat kepercayaan dari para pelanggan nya[11]. Pola konsumsi dan gaya hidup pelanggan menuntut perusahaan atau usaha mikro mampu memberikan pelayanan yang sangat berkualitas. Keberhasilan perusahaan atau usaha mikro dalam memberikan pelayanan yang berkualitas dapat ditentukan dengan pendekatan service quality. Service quality adalah seberapa jauh perbedaan antara harapan dan kenyataan para pelanggan atas pelayanan yang mereka terima[12]. Service quality dapat diketahui dengan cara membandingkan persepsi pelanggan atas pelayanan yang benar-benar mereka terima dengan layanan sesungguhnya yang mereka harapkan. Kualitas pelayanan menjadi hal pertama yang diperhatiakn serius oleh perusahaan, yang melibatkan seluruh sumber daya yang dimiliki perusahaan[13].

\section{c. Harga}

Harga menjadi faktor utama yang dapat mempengaruhi pilihan seorang pembeli, harga cukup berperan dalam menentukan pembelian kosumen, untuk itu sebelum menetapkan suatu harga, sebaiknya perusahaan melihat beberapa referensi harga suatu produk yang dinilai cukup tinggi dalam penjualan[14].

Perusahaan harus menetapkan harga sesuai dengan nilai yang diberikan dan dipahami pelanggan. Jika harganya ternyata lebih tinggi daripada nilai yang diterima, perusahaan tersebut akan kehilangan kemungkinan untuk memetik laba, jika harganya ternyata terlalu rendah daripada nilai yang diterima, perusahaan tersebut tidak akan berhasil menuai kemungkinan memperoleh laba[15].

\section{d. Lokasi}

Lokasi adalah tempat dimana perusahaan harus bermrkas dan melakukan operasi[7], [16]. Memilih lokasi berdagang merupakan keputusan 
penting untuk bisnis yang harus membujuk pelanggan untuk datang ketempat bisnis dalam pemenuhan kebutuhannya. Pemilihan lokasi mempunyai fungsi yang strategis karena dapat ikut menentukan tercapainya tujuan badan usaha.

Hipotesis akan diuji oleh peneliti dengan menggunakan pendekatan kuantitatif.

$\mathrm{H}_{1}$ : Kualitas Pelayanan $\left(\mathrm{X}_{1}\right)$ berpengaruh secara signifikan terhadap Kepuasan Kosumen (Y)

$\mathrm{H}_{2}$ : Harga $\left(\mathrm{X}_{2}\right)$ berpengaruh secara signifikan terhadap Kepuasn Konsumen (Y)

$\mathrm{H}_{3}$ : Lokasi $\left(\mathrm{X}_{3}\right)$ berpengaruh secara signifikan terhadap Kepuasn Konsumen (Y)

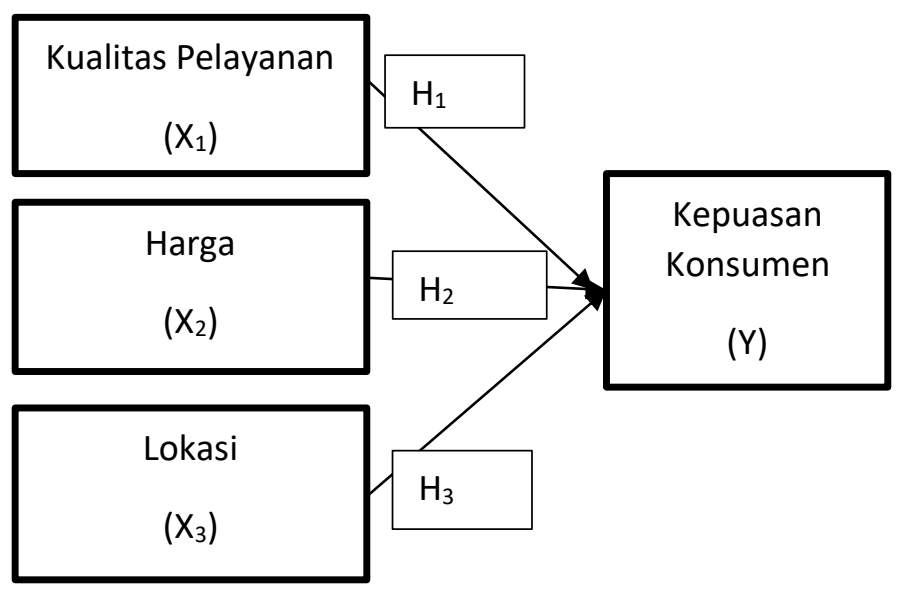

Gambar 1. Model Penelitian

\section{METODE PENELITIAN}

Metode penelitian yang digunakan adalah metode penelitian dengan menggunakan pendekatan kuantitatif dengan cara mengumpulkan data menggunakan teknis survey. Tujuan penelitian ini untuk mengetahui pengaruh antara variabel bebas (kualitas pelayanan, harga dan lokasi) dengan variabel terkait (kepuasan konsumen). Populasi dalam penelitian ini adalah semua konsumen usaha mikro yang telah membeli produk lebih dari satu kali transaksi di pasar dengan jumlah populasi yang tidak diketahui. Sampel yang ditentukan berjumlah 100 orang menggunakan teknik nonprobability sampling.

\section{HASIL DAN PEMBAHASAN}

\section{a. Analisis Regresi Liner Berganda}

Terdapat nilai koefisien regresi dengan melihat hasil pada tabel coefficient pada kolom unstandardized dalam kolom B.

\section{Tabel 1. Coefficients}

\begin{tabular}{|c|c|c|c|c|c|}
\hline & \multicolumn{2}{|c|}{$\begin{array}{l}\text { Unstandardiz } \\
\text { ed } \\
\text { Coefficients }\end{array}$} & \multirow{2}{*}{$\begin{array}{c}\text { Standardize } \\
\mathrm{d} \\
\text { Coefficient } \\
\mathrm{s} \\
\text { Beta } \\
\end{array}$} & \multirow[b]{2}{*}{$\mathrm{T}$} & \multirow[b]{2}{*}{ Sig } \\
\hline Model & B & $\begin{array}{l}\text { Std. } \\
\text { Error }\end{array}$ & & & \\
\hline 1 (Constant) & 2,152 & 1,733 & & $\begin{array}{r}1,24 \\
2 \\
\end{array}$ & $\begin{array}{r}, 21 \\
7 \\
\end{array}$ \\
\hline $\begin{array}{l}\text { KUALITAS } \\
\text { PELAYANA } \\
\mathrm{N}\end{array}$ & ,297 & ,090 & ,290 & $\begin{array}{r}3,31 \\
0\end{array}$ & $\begin{array}{r}, 00 \\
1\end{array}$ \\
\hline HARGA & ,392 & ,097 & ,320 & $\begin{array}{r}4,05 \\
1 \\
\end{array}$ & $\begin{array}{r}, 00 \\
0 \\
\end{array}$ \\
\hline LOKASI & ,272 & ,067 & ,346 & $\begin{array}{r}4,07 \\
0 \\
\end{array}$ & $\begin{array}{r}, 00 \\
0\end{array}$ \\
\hline
\end{tabular}

a. Dependent Variable: TOTAL_Y

Dalam sub kolom tersebut terdapat nilai constant (konstanta), dengan nilai konstanta sebesar 2,152 sedangkan nilai koefisien regresi untuk Kualitas Pelayanan $(X 1)=0,297$, Harga $(X 2)=0,392$, dan Lokasi $(X 3)=0,272$.

Berdasarkan hasil tersebut maka dapat dirumuskan model persamaan regresi berganda dalam penelitian ini yang kemudian akan diinterprestasikan makna dari model persamaan regresi tersebut. Adapun model persamaan regresi tersebut adalah sebagai berikut:

$$
\begin{aligned}
& \mathrm{Y}=\mathrm{a}+\mathrm{bX} 1+\mathrm{bX} 2+\mathrm{bX} 3 € \mathrm{Y} \\
& \mathrm{Y}=2,152+0,297 \mathrm{X}_{1}+0,392 \mathrm{X}_{2}+0,272 \mathrm{X}_{3}
\end{aligned}
$$

Berdasarkan persamaan dapat diketahui bahwa :

1. Nilai koefisien regresi variabel kualitas pelayanan sebesar 0,297 bernilai positif mempunyai arti bahwa jika persepsi terhadap kualitas pelayanan semakin baik, maka kepuasan pelanggan akan meningkat.

2. Nilai koefisien regresi variabel harga sebesar 0,392 bernilai positif mempunyai arti bahwa jika persepsi terhadap harga semakin baik, maka kepuasan pelanggan akan meningkat.

3. Nilai koefisien regresi variabel pelayanan sebesar 0,272 bernilai positif mempunyai arti bahwa jika persepsi terhadap lokasi semakin baik, maka kepuasan pelanggan akan meningkat. 


\section{b. Uji Parsial (Uji T)}

Uji t bertujuan untuk mengetahui apakah variabel bebas atau Kualitas Pelayanan (X1),

Tabel 2. Hasil Uji T

\begin{tabular}{|c|c|c|c|c|c|c|}
\hline \multirow{2}{*}{\multicolumn{2}{|c|}{ Model }} & \multirow{2}{*}{\multicolumn{2}{|c|}{$\begin{array}{l}\text { Unstandardized } \\
\text { Coefficients } \\
\text { Std. }\end{array}$}} & \multirow[t]{2}{*}{$\begin{array}{c}\text { Standar } \\
\text { dized } \\
\text { Coeffici } \\
\text { ents }\end{array}$} & & \multirow[b]{2}{*}{ Sig. } \\
\hline & & & & & & \\
\hline 1 & (Constant) & 2,152 & 1,733 & & $\begin{array}{r}1,24 \\
2\end{array}$ & ,217 \\
\hline & $\begin{array}{l}\text { KUALITAS } \\
\text { PELAYANA } \\
\mathrm{N}\end{array}$ & ,297 & ,090 & ,290 & $\begin{array}{r}3,31 \\
0\end{array}$ & ,001 \\
\hline & HARGA & ,392 & ,097 & ,320 & $\begin{array}{r}4,05 \\
1\end{array}$ &, 000 \\
\hline & LOKASI & ,272 & ,067 & ,346 & $\begin{array}{r}4,07 \\
0 \\
\end{array}$ &, 000 \\
\hline
\end{tabular}

a. Dependent Variable: TOTAL_Y

Tabel 3. ANOVA

\begin{tabular}{llr|r|r|r|r}
\hline \multicolumn{1}{l}{ Model } & $\begin{array}{r}\text { Sum of } \\
\text { Squares }\end{array}$ & Df & $\begin{array}{c}\text { Mean } \\
\text { Square }\end{array}$ & F & Sig. \\
\hline $1 \quad \begin{array}{l}\text { Regress } \\
\text { ion }\end{array}$ & $\begin{aligned} 1044,10 \\
0\end{aligned}$ & 3 & 348,033 & 98,08 &, $000^{b}$ \\
& $\begin{array}{l}\text { Residu } \\
\text { al }\end{array}$ & 340,650 & 96 & 3,548 & & \\
\hline Total & $\begin{array}{r}1384,75 \\
0\end{array}$ & 99 & & & \\
\hline
\end{tabular}

a. Dependent Variable: TOTAL_Y

b. Predictors: (Constant), LOKASI, HARGA, KUALITAS PELAYANAN

Harga (X2) dan Lokasi (X3) secara parsial ataupun individual berpengaruh signifikan terhadap variabel terikat atau Kepuasan Konsumen (Y). Pengaruh dari masing-masing variabel dapat dijelaskan sebagai berikut:

1. Pengaruh Kualitas Pelayanan terhadap Kepuasan Konsumen

Hasil uji t pada variabel kualitas pelayanan atau X1 diperoleh probabilitas Sig sebesar 0,001. Nilai Sig < $0,05(0,001<0,05)$, maka keputusannya adalah H0ditolak dan Ha diterima, artinya signifikan yang berarti secara parsial Kualitas Pelayanan berpengaruh signifikan terhadap Kepuasan Konsumen. Sementara itu variabel Kualitas Pelayanan atau X1 mempunyai thitung yakni 3,310 dengan tabel $=1,661$ (one tailed test). Jadi thitung > ttabel dapat disimpulkan bahwa variabel X1 memiliki kontribusi terhadap Y.

2. Pengaruh Harga terhadap Kepuasan Konsumen

Hasil uji t pada variabel kualitas pelayanan atau X1 diperoleh probabilitas Sig sebesar 0,001. Nilai Sig < $0,05(0,001<0,05)$, maka keputusannya adalah HOditolak dan Ha diterima, artinya signifikan yang berarti secara parsial Kualitas Pelayanan berpengaruh signifikan terhadap Kepuasan Konsumen. Sementara itu variabel Kualitas Pelayanan atau X1 mempunyai thitung yakni 4,051 dengan ttabel $=1,661$ (one tailed test). Jadi thitung $>$ ttabel dapat disimpulkan bahwa variabel X1 memiliki kontribusi terhadap Y.

3. Pengaruh Lokasi terhadap Kepuasan Konsumen

Hasil uji t pada variabel kualitas pelayanan atau X1 diperoleh probabilitas Sig sebesar 0,001. Nilai Sig < $0,05(0,001<0,05)$, maka keputusannya adalah HOditolak dan Ha diterima, artinya signifikan yang berarti secara parsial Kualitas Pelayanan berpengaruh signifikan terhadap Kepuasan Konsumen. Sementara itu variabel Kualitas Pelayanan atau X1 mempunyai thitung yakni 4,070 dengan ttabel $=1,661$ (one tailed test). Jadi thitung > ttabel dapat disimpulkan bahwa variabel X1 memiliki kontribusi terhadap Y

\section{c. Uji Simultan (Uji F)}

Dalam melakukan uji F, parameter yang digunakan adalah dengan membandingkan F-hitung > F-tabel. Pengujian terhadap pengaruh variabel bebas terhadap variabel terikat secara simultan dilakukan dengan uji F.

Anova di peroleh nilai probabilitas (Sig) sebesar 0,000. Karena nilai Sig $<0,05(0,000<0,05)$, maka keputusannya adalah $\mathrm{H} 0$ ditolak dan $\mathrm{Ha}$ diterima. Kesimpulan nya signifikan artinya $F_{\text {hitung }} 98,081$ bahwa Kualitas Pelayanan, Harga dan Lokasi secara bersamasama atau secara simultan berpengaruh signifikan terhadap Kepuasan Konsumen pada usaha mikro di pasar.

Berdasarkan analisis yang telah didapatkan, maka kualitas pelayanan, harga dan lokasi secara parsial berpengaruh signifikan terhadap kepuasan konsumen usaha mikro. Berdasarkan hasil uji $\mathrm{F}$ dapat disimpulkan bahwa kualitas pelayanan, harga dan lokasi secara simultan berpengaruh signifikan terhadap kepuasan konsumen usaha mikro.

\section{KESIMPULAN DAN SARAN}

Dalam menjalankan sebuah bisnis, kualitas pelayanan, harga dan lokasi merupakan indikator yang sangat strategis dalam meningkatkan kepuasan konsumen baik usaha kecil maupun menengah. Hal ini 
merupakan temuan yang dapat memperkuat bahwa faktor kualitas pelayanan, harga dan lokasi menjadi salah satu strategi bisnis yang bersifat strategis. Kepuasan konsumen juga harus menjadi perhatian untuk selalu dikelola oleh pelaku bisnis agar bisnisnya dapat berkelanjutan. Dinamis dan adaptif menjadi salah satu kata kunci yang perlu dijaga oleh pelaku bisnis dalam menjalankan usahanya.

\section{REFERENSI}

[1] N. A. Hamdani and S. Nugraha, "The influence of information technology and entrepreneurial orientation on competitiveness and business performance," in Advances in Business, Management and Entrepreneurship, London: Taylor \& Francis Group, LLC, 2020, pp. 565569.

[2] J. Zhang and Y. Duan, "Empirical study on the impact of market orientation and innovation orientation on new product performance of Chinese manufacturers," Nankai Business Review International, vol. 1, no. 2. pp. 214231, 2010, doi: 10.1108/20408741011052609 LK

https://doi.org/10.1108/20408741011052609.

[3] K. L. Kotler, Philip dan Keller, Marketing Management, 14th ed. New Jersey: Pearson, 2012.

[4] B. B. Ateba, K. Ohei, A. Maredza, P. Deka, and D. Schutte, "Marketing mix: it' $s$ role in customer satisfaction in the South African banking retailing," Banks Bank Syst., vol. 10, no. 1, pp. 83-91, 2015.

[5] H. Samhah, "PENGARUH KUALITAS LAYANAN DAN HARGA TERHADAP KEPUASAN KONSUMEN OOST KAFE SURABAYA," J. Ilmu dan Ris. Manaj. , vol. 5, no. 12, pp. 1-17, 2016.

[6] A. Hamdani and G. A. Fatah, "Perencanaan Strategis Sistem Informasi pada Usaha Kecil dan Menengah," vol. 4, no. September, pp. 167-172, 2018.

[7] P. Kotler and L. L. Keller, Marketing Management, 14th ed. England: Pearson Education Limited, 2013.

[8] N. Arie Sulistyawati and N. Seminari, "Pengaruh Kualitas Pelayanan Terhadap
Kepuasan Pelanggan Restoran Indus Ubud Gianyar," E-Jurnal Manaj. Univ. Udayana, vol. 4, no. 8, p. 250437, 2015.

[9] A. Gofur, "Pengaruh Kualitas Pelayanan Dan Harga Terhadap Kepuasan Pelanggan," J. Ris. Manaj. dan Bisnis Fak. Ekon. UNIAT, vol. 4, no. 1, pp. 37-44, 2019, doi: 10.36226/jrmb.v4i1.240.

[10] E. A. Amangala and A. F. Wali, "Market Orientation, Service Quality Perception, and Customer Satisfaction: The Role of Marketsensing Capabilities," Business Perspectives and Research, vol. 8, no. 2. pp. 216-231, 2020, doi: $10.1177 / 2278533719887453$ LK https://doi.org/10.1177/2278533719887453.

[11] R. W. Y. Yee, A. C. L. Yeung, and T. C. Edwin Cheng, "An empirical study of employee loyalty, service quality and firm performance in the service industry," Int. J. Prod. Econ., vol. 124, no. 1, pp. 109-120, 2010, doi: 10.1016/j.ijpe.2009.10.015.

[12] H. Rohaeni and N. Marwa, "Kualitas Pelayanan Terhadap Kepuasan Pelanggan," J. Ecodemica J. Ekon. Manajemen, dan Bisnis, vol. 2, no. 2, pp. 1-7, 2018, doi: 10.31311/JECO.V2I2.4503.

[13] D. T. P. Singh, "Measuring Service Quality Effect on Consumer Purchase Intention in Retailing," International Journal of Modern Agriculture, vol. 9, no. 3. Auricle Technologies, Pvt., Ltd., pp. 375-388, 2020, doi: 10.17762/ijma.v9i3.162.

[14] Eugene F. Brigham dan J.F. Houston, "DasarDasar Manajemen Keuangan. Edisi 11.," Jakarta : Salemba Empat., 2010.

[15] A. Amron, "Effects of Product Quality, Price, and Brand Image on the Buying Decision of City Car Product," Arch. Bus. Res., vol. 6, no. 4, pp. 1-8, 2018, doi: 10.14738/abr.64.4374.

[16] B. Türk and A. Erciş, "4A marketing mix impacts on organic food purchase intention," Serbian Journal of Management, vol. 12, no. 2. Centre for Evaluation in Education and Science (CEON/CEES), pp. 189-199, 2017, doi: 10.5937/sjm12-10785. 